\title{
Probiotic Therapy for Prevention of Necrotizing Enterocolitis in Preterm Infants - A Review
}

\author{
S Sarkar* \\ Manager (Quality Assurance), Metro Dairy Limited, Barrackpore-Barasat Link Road, Subhasnagar, P.O. Neelgunj Bazar, \\ Kolkata-700121, West Bengal, India
}

Received: June 01, 2018; Accepted: June 25, 2018; Published: June 29, 2018

*Corresponding author: S Sarkar, Manager (Quality Assurance), Metro Dairy Limited, Barrackpore-Barasat Link Road, Subhasnagar, P.O. Neelgunj Bazar, Kolkata-700121, West Bengal, India, Tel: +919830233400, E-mail: drsurajitsarkar@yahoo.co.in

\begin{abstract}
Purpose: Preterm infants are prone to systemic infections due to increased intestinal permeability to potentially pathogens resulting from immature intestinal function, frequent use of broad-spectrum antibiotics, delay in initiating enteral feeding, infection control procedures and sterilization of milk. Very Low Birth Weight infants, particularly Extremely Low Birth Weight infants are at higher risk due to abnormal pattern of colonization, which may contribute to the pathogenesis of neonatal Necrotizing Enterocolitis (NEC). Dietary intervention through probiotic supplementation is widely adopted for the prophylaxis of NEC and nosocomial infections throughout the world.
\end{abstract}

Design/Methodology/Approach: This review paper is based upon systematic review of randomized controlled trials, metaanalyses, research papers and books related to the short and longterm administration of single or mixed probiotic cultures for the prevention of NEC only in preterm infants. Clinical trials and cohort studies concerning manipulation of the intestinal microbiota in premature infants are also included. Evidence based data published in the English language retrieved from three databases Pub Med, Science Direct and Cochrane Reviews, published in The Cochrane Library from 2000-2016, using a combination of key words like necrotizing enterocolitis, probiotics and preterm infants have been considered.

Findings: All probiotic strains are not equally efficacious for preventing NEC and application of probiotic combinations may be advantageous. Due to heterogeneity of probiotic formulations exclusive administration of probiotics in premature infants is not recommended and should be introduced along with breast milk as routine clinical practice for neonatal health care.

Originality/Value: Probiotic foods have been found effective in modulating gastrointestinal flora to prevent NEC but safety aspects must be evaluated prior to consideration of probiotic therapy for preterm infants and neonates.

Keywords: Probiotic therapy; necrotizing enterocolitis; preterm infants; dietary intervention

\section{Introduction}

Breast milk is considered the most ideal food for infants owing to its nutrition attributes, immune factors, growth factors, digestive enzymes, hormones, bioactive factors such as antibodies, Immunoglobulin M, Immunoglobulin G and IgA and antibacterial proteins/peptides such as lysozyme and lactoferrin [1-3]. Human milk is also equally suitable for the management of premature infants and mother's own milk should be the first choice. Mother's milk does not alone provide optimal nutrition and requires appropriate fortification to meet the growth and neuro-developmental requirements [4-6].

Reviewed literature revealed that preterm infants are prone to systemic infections due to increased intestinal permeability to potentially pathogens resulting from immature intestinal function, frequent use of broad-spectrum antibiotics, delay in initiating enteral feeding, infection control procedures and sterilization of milk [7]. Abnormal pattern of colonization in Very Low Birth Weight (VLBW) infants with birth weight $<1500 \mathrm{~g}$ and particular in Extremely Low Birth Weight (ELBW) infants with birth weight $<1000 \mathrm{~g}$ are at higher risk and may contribute to the pathogenesis of neonatal Necrotizing Enterocolitis (NEC), an acquired Gastrointestinal (GI) disease associated with significant morbidity and mortality. NEC infected infants develop intestinal injury, which permits bacteria and bacterial by-products to cross the mucosal barrier and disseminate to the bloodstream via the lymph system, resulting in sepsis, shock, multi-system organ failure and potentially death $[8,9]$.

Incidences of NEC in premature infant can be reduced by manipulating the composition of the intestinal microbiota and expression of gut microbial genes through most promising interventions like human milk, probiotics and lactoferrin [10]. Amongst modern therapeutic strategies, the probiotic approach of modulating the gut flora to re-establish the normal health has gained much creditability due to their capability for colonizing the gut, restoration of normal microflora, re-establishment of the intestinal barrier function, induction of homeostasis of immune system, normalization of the digestive functioning, providing several trace nutritive elements anti-inflammatory action to the host improvement in feeding intolerance, prevention of sepsis and NEC [11-17]. Dietary intervention through probiotic supplementation is widely adopted worldwide for prophylaxis of NEC and nosocomial infections [18].

Diverse commercial probiotic products offered to VLBW infants in neonatal intensive care unit (NICU) are not capable 
of exhibiting protective effect against NEC and even certain probiotic products do not have declaration regarding probiotics or contains active organisms [19-22]. It can thus be interpreted that all probiotic products available in the market and all probiotic cultures are not equally effective against NEC prevention. In the present review, attempt has been made to highlight the health benefits of probiotics for NEC prevention and its safety concern for preterm infants.

\section{Colonization of Gut}

At birth the intestinal flora of human is sterile and is subsequently colonized by vaginal and faecal flora of mothers during birth [23, 24]. Development of the intestinal microbiota of infants is characterized by rapid and large changes in microbial abundance, diversity and composition and is influenced by medical, cultural and environmental factors such as mode of delivery, diet, familial environment, diseases and therapies used [25]. A balance between commensal and pathogenic bacteria is of utmost importance for normal function, immunology and homeostasis in the healthy intestine and any disruption of this balance may lead to disease conditions [26].

Gut colonization pattern of preterm infants is different from normal infants and is influenced by nutritional, immunological and environmental factors [27, 28]. Predominance of gut with beneficial flora like Bifidobacterium, Lactobacillus and Bacteroides in normal infants and potentially pathogenic bacteria such as Enterobacteriaceae and Clostridium species in preterm infants were reported [29-32]. Preterm, especially ELBW infants lack transplacental transfer of maternal antibodies and are at greater risk for aberrant colonization due to non-vaginal births, exposure to abnormal environmental pathogens at intensive care unit, delayed and/or sterile feeding, prolonged antibiotic exposure, greater infection control practices lack of typical skin contact with maternal flora as well as alterations in typical exposure to breast milk $[27,29,33,34]$. Preterm infants lack adequate intestinal commensal or "healthy" bacterial flora and abnormal pattern of colonization in preterm infants may contribute to the pathogenesis of NEC. Various pathways for early patterns of microbial colonization are enumerated below $[27,30]$.

- Enhancement of the mucosal protective barrier

- Modification of systemic immune response

- Competitive exclusion of less desirable microbe

- Protein and carbohydrate degradation

- Vitamin and butyrate production

- Mucosal differentiation

\section{Probiotics for Preterm Infants}

Probiotics are live microorganisms that when administered in adequate amounts confer a health benefit on the host [35]. This definition is widely accepted and adopted by the International Scientific Association for Probiotics and Prebiotics [36]. Dani et al. suggested restriction of growth of pathogens by colonization of the intestine with non-pathogenic and normal resident bacterial species (probiotics) of gut bacteria in preterm and term infants [37]. Probiotics may promote intestinal function, maturation and defense against potential harmful pathogens and most systematic reviews reported probiotic to be safe and efficacious and can be recommend for routine administration in the preterm infants $[17,38,39]$.

Raguz et al. reported shorter stay time in intensive care, early full peroral intake of milk and shorter time of treatment with anti-ulcer medicine due to administration of probiotics in premature infants [40]. Introduction of probiotics resulted in lower mortality and lower frequency of infection reduces the risk of Late-Onset Sepsis (LOS) in premature infants [41, 42, 43]. Rijkers, et al. categorized the diverse health benefits extended by probiotics into three groups [44].

- Probiotic microorganisms act directly within the GI tract through direct interaction with the intestinal microbiota or by enzymatic activities.

- Probiotic microorganisms interact directly with the intestinal mucus layer and epithelium thereby influencing the intestinal barrier function and the mucosal immune system.

- Probiotic microorganisms can have effects outside the GI tract such as on the systemic immune system and other organs.

Demonstrated health benefits for specific probiotic strains of genera: Lactobacillus, Bifidobacterium, Saccharomyces, Enterococcus, Streptococcus, Pediococcus, Leuconostoc, Bacillus, Escherichia coli have been reported [45]. Rouge et al. reported that supplementation of Lactobacillus rhamnosus GG and Bifidobacterium longum BB536 failed to colonize in ELBW infants and may not improve the gastrointestinal tolerance to enteral feeding in VLBW infants [46]. Reviewed literature and research findings indicated that all probiotic cultures and their dosages are not effective in preventing NEC in preterm neonates (Table 1). Meta analysis of randomized controlled trials indicated that probiotic supplementation was associated with a significant decrease in risk of NEC and mortality in preterm VLBW infants. AlFaleh and Anabrees reported that probiotic supplementation was associated with significantly reduction in the incidence of severe NEC (typical RR $0.35,95 \%$ CI 0.24 to 0.52 ) and mortality (typical RR $0.55,95 \%$ CI 0.40 to 0.74 ) [75]. Another Meta analysis showed a significantly decreased risk of NEC in preterm VLBW infants (RR $=0.47 ; 95 \% \mathrm{CI}: 0.35-0.62 ; P<0.001$ ) as well as risk of mortality (RR=0.63; 95\%CI: $0.51-0.78 ; P<0.01)$ due to probiotic supplement [76]. A significant decrease in incidence of NEC (risk ratio, $\mathrm{RR}=0.55,95 \%$ confidence interval, 95\% CI, 0.39-0.78; $\mathrm{p}=$ 0.0006 ) and mortality (RR $=0.72,95 \% \mathrm{CI}, 0.61-0.85 ; \mathrm{P}<0.0001$ ) but no evidence of significant decrease in the risk for sepsis (RR $=0.86,95 \% \mathrm{CI}, 0.74-1.00 ; \mathrm{p}=0.05$ ) could be noted in premature neonates receiving prophylactic probiotics [77]. Recently, in a randomized controlled trial, preterm neonates fed with oral probiotics containing Saccharomyces boulardi, L. rhamanosus, Lactobacillus acidophilus, B. longum and Streptococcus thermophilus along with breast milk exhibited a greater decline in both incidence (2.7 vs. $9.3 \%$ ) and severity (Stage 1: 2 vs. $3.3 \%$ and Stage 2: 1 vs. $9 \%$ ) of NEC in contrast to neonates fed exclusively with breast milk [72]. 
Table -1: Effect of probiotic dosages on necrotising enterocolitis in preterm neonates

\begin{tabular}{|c|c|c|}
\hline Dosage of Probiotic organisms & Observations & References \\
\hline Lactobacillus GG $\left(10^{8} \mathrm{cfu} /\right.$ twice daily $)$ & No effect on NEC & 47 \\
\hline $\begin{array}{l}\text { L. acidophilus }\left(2.0 \times 10^{8} \mathrm{cfu} / \text { day }\right) \\
\text { B. infantis }\left(2.0 \times 10^{8} \mathrm{cfu} / \text { day }\right)\end{array}$ & Reduced NEC & 48 \\
\hline 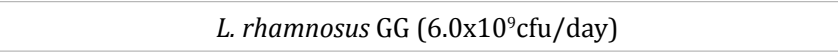 & Reduced NEC & 37 \\
\hline $\begin{array}{l}\text { B. infantis }\left(0.35 \times 10^{9} \mathrm{cfu} / \text { day }\right) \\
\text { S. thermophilus }\left(0.35 \times 10^{9} \mathrm{cfu} / \mathrm{day}\right) \\
\quad \text { B. bifidus }\left(0.35 \times 10^{9} \mathrm{cfu} / \mathrm{day}\right)\end{array}$ & Reduced NEC & 49 \\
\hline $\begin{array}{l}\text { L. acidophilus }\left(2.0 \times 10^{8} \mathrm{cfu} / \text { day }\right) \\
\text { B. infantis }\left(2.0 \times 10^{8} \mathrm{cfu} / \text { day }\right)\end{array}$ & Reduced NEC & 50 \\
\hline L. acidophilus $\left(10^{8} \mathrm{cfu} / \mathrm{ml}\right)$ & No significant effect on NEC & 51 \\
\hline $\begin{array}{l}\text { L. acidophilus }\left(10^{9} \mathrm{cfu} / \text { twice daily }\right) \\
\text { B. bifidus }\left(10^{9} \mathrm{cfu} / \text { twice daily }\right)\end{array}$ & Reduced NEC & 52 \\
\hline L. rhamnosus $\mathrm{GG}+B$. longum $\left(1 \times 10^{8} \mathrm{cfu}\right)$ & No effect on NEC & 46 \\
\hline L. rhamnosus GG $\left(6.0 \times 10^{9} \mathrm{cfu} / \mathrm{day}\right)$ & Reduced NEC & 54 \\
\hline Lactobacillus sporogenes $\left(3.5 \times 10^{8} \mathrm{cfu} /\right.$ day $)$ & Reduced NEC & 55 \\
\hline $\begin{array}{l}\text { L. casei }\left(3.5 \times 10^{7} \text { to } 3.5 \times 10^{9} \mathrm{cfu} / \text { day }\right) \\
\text { B. breve }\left(3.5 \times 10^{7} \text { to } 3.5 \times 10^{9} \mathrm{cfu} / \text { day }\right)\end{array}$ & Reduced NEC & 56 \\
\hline B. lactis BB $12\left(2 \times 10^{9} \mathrm{cfu} / \mathrm{kg}\right.$ for 6 weeks $)$ & Reduced NEC & 57 \\
\hline 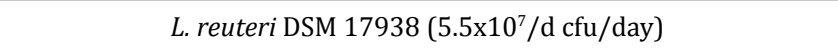 & Reduced NEC & 58 \\
\hline L. rhamnosus $G G\left(0.5 \times 10^{9}+\right.$ B.infantis $\left(0.5 \times 10^{9}\right.$ daily $)$ & No effect on NEC & 59 \\
\hline $\begin{array}{c}\text { L. acidophilus }\left(1.0 \times 10^{9}\right)+\text { L. reuteri }\left(4.4 \times 10^{8}\right)+\text { L. casei }\left(1.0 \times 10^{9}\right)+L \text {. } \\
\text { planatarum }\left(1.76 \times 10^{8}\right)+\text { B. Infantis }\left(2.76 \times 10^{7}\right)+S \text {. thermophillus } \\
\left(6.6 \times 10^{5} \mathrm{cfu} / \text { day }\right)\end{array}$ & No effect on NEC & 60 \\
\hline Saccharomyces thermophilus + B.infantis + B. bifidum & Reduced NEC & 41 \\
\hline 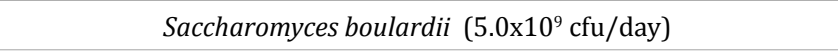 & No significant effect on NEC & 61 \\
\hline 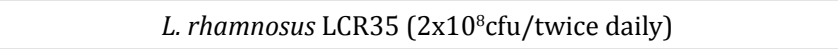 & Reduced NEC & 62 \\
\hline Saccharomyces boulardii $\left(5 \times 10^{8} \mathrm{cfu} / \mathrm{kg} /\right.$ twice daily $)$ & No effect on NEC & 63 \\
\hline $\begin{array}{l}\text { B. infantis }\left(3 \times 10^{8} \mathrm{cfu} / \text { day }\right) \text {, S. thermophilus }\left(3.5 \times 10^{8} \mathrm{cfu} / \text { day }\right) \text {, B. lactis } \\
\qquad\left(3.5 \times 10^{8} \mathrm{cfu} / \text { day }\right)\end{array}$ & Reduced NEC & 64 \\
\hline B. breve $\mathrm{BBG}-001\left(2.1-5.3 \times 10^{8} \mathrm{cfu} / \mathrm{day}\right)$ & Reduced NEC & 65 \\
\hline L. acidophilus $+B$. Infantis $\left(1 \times 10^{9} / \mathrm{d}\right.$ for 14 days $)$ & No effect on NEC & 18 \\
\hline $\begin{array}{l}\text { L. rhamnosus } \mathrm{GG}, \text { B. breve, B. bifidum, B. infantis, } \\
\text { B. longum }\left(2 \times 10^{9} \mathrm{cfu} / \text { day until } 34 \text { weeks }\right)\end{array}$ & Reduced NEC & 66 \\
\hline Bovine Lactoferrin + L. rhamnosus GG $\left(3 \times 10^{9} \mathrm{cfu} /\right.$ day $)$ & Reduced NEC & 67 \\
\hline L. reuteri DSM 17938 (1×10다/daily) & Reduced NEC & 68 \\
\hline $\begin{array}{l}\text { L. acidophilus }\left(10^{9} \mathrm{cfu} / \text { twice daily }\right)+B \text {. bifidum } \\
\qquad\left(10^{9} \mathrm{cfu} / \text { twice daily }\right)\end{array}$ & No effect on NEC & 69 \\
\hline $\begin{array}{l}\text { L. acidophilus }\left(10^{9} \mathrm{cfu} / \text { day }\right) \\
\text { B. infantis }\left(10^{9} \mathrm{cfu} / \mathrm{day}\right)\end{array}$ & Reduced NEC & 70 \\
\hline B. lactis $\left(5.0 \times 10^{9} \mathrm{cfu} / \mathrm{day}\right)$ & Reduced NEC & 71 \\
\hline $\begin{array}{l}\text { Saccharomyces boulardi } 250 \mathrm{mg} \text {, } \\
\text { L. rhamanosus }\left(2.4 \times 10^{8} \mathrm{cfu} / \text { twice daily }\right) \\
\text { L. acidophilus }\left(2.4 \times 10^{8} \mathrm{cfu} / \text { twice daily }\right) \\
\text { B. longum }\left(2.4 \times 10^{8} \mathrm{cfu} / \text { twice daily }\right) \\
\text { S. thermophilus }\left(2.4 \times 10^{8} \mathrm{cfu} / \text { twice daily }\right)\end{array}$ & Reduced NEC & 72 \\
\hline
\end{tabular}




\begin{tabular}{|c|c|}
\hline $\begin{array}{c}\text { L. acidophilus }\left(6 \times 10^{9} \mathrm{cfu} / \mathrm{day}\right) \\
\text { Bifidobacterium ssp. }\left(6 \times 10^{9} \mathrm{cfu} / \mathrm{day}\right)\end{array}$ & Reduced NEC \\
\hline B. breve BBG $\left(1.6 \times 10^{8}-1.6 \times 10^{9} /\right.$ day until 36 weeks $)$ & Reduced NEC \\
\hline
\end{tabular}

Recommended probiotics for administration in preterm infants are Lactobacillus reuteri, Lactobacillus casei, L. rhamnosus GG, L. acidophilus, B. infantis, Lactobacillus GG, Bifidobacterium breve, Lactobacillus paracasei subsp. paracasei $[77,78]$. In order to reduce NEC and mortality in preterm infants, it is advisable to add routine prophylaxis with dual-strain probiotics such as a combination of $L$. casei and B. breve, Bifidobacterium infantis, Lactobacillus and Bifidobacterium lactis or L. acidophilus and Bifidobacterium spp. [56, 79, 80]. The Latin American Expert group consensus recommends the use of $B$. breve, mixtures of Bifidobacterium and Streptococcus, L. rhamnosus GG, L. acidophilus and L. reuteri DSM 17938 for the prevention of NEC [81]

\section{Mechanism of Prophylactic Effect of Probiotics on NEC}

Postulated mechanisms of probiotics that can be put forward towards prevention of development of sepsis and NEC in preterm infants are:

- Enhanced barrier to migration of bacteria and their products across the mucosa $[82,83]$

- Competitive exclusion of potential pathogens [84]

- Modification of host response to microbial products [85]

- Augmentation of IgA mucosal responses

- Enhancement of enteral nutrition that inhibits the growth of pathogens and upregulation of immune responses $[86,87]$

- promoting colonisation with beneficial organisms

- modulating the immune system to the advantage of the host [35, 88]

- binding sites and substrate in the bowel, which increases the production of anti-inflammatory cytokines, decreases the production of pro-inflammatory cytokines and reduces intestinal permeability $[27,89]$

\section{Safety of Probiotics for Preterm Infants}

In general, the microorganisms used in the production of food fermentation have a long history of safe use and are often referred to as "food grade" or Generally Recognized as Safe (GRAS) microorganisms [90]. Probiotics extends numerous health benefits but theoretically they may have diverse types of side effects such as systemic infections, deleterious metabolic activities, excessive immune stimulation in susceptible individuals, gene transfer interference or alteration of commensal microflora by exogenous probiotic cultures and sepsis, fungemia and GI ischemia [91-95]. FAO/WHO recommends that probiotic strains must be characterized for the following tests for recognition as GRAS [96].

- Determination of antibiotic resistance patterns
-Assessment of certain metabolic activities (D-lactate production, bile salt deconjugation)

- Assessment of side-effects during human studies

- Epidemiological surveillance of adverse incidents in consumers (post-market)

- If the strain under evaluation belongs to a species that is a known mammalian toxin producer, it must be tested for toxin production.

- If the strain under evaluation belongs to a species with known hemolytic potential, determination of hemolytic activity is required

ESPGHAN Committee on Nutrition declared that administration of commercially prepared probiotic/probiotic formulas is safe for healthy infants and more data is required for its routine use in healthy infants and for VLBW infants [97]. Based upon the level of evidence American Pediatric Surgical Association Outcomes and Clinical Trials Committee recommended routine supplementation of probiotics in premature infants but made no formal recommendations regarding the formulation, timing or duration of supplementation, however administration of at least one probiotic formulation at least for a period of 2 weeks, initiated from the first week of life is suggested [98]. Probiotics have been recommended as a routine therapy for preterm neonates and an initial dosage of $1.5 \times 10^{9} \mathrm{cfu} /$ day for ELBW neonates until they reach enteral feeds of $50-60 \mathrm{ml} / \mathrm{kg} /$ day followed by an augmentation in dosages to $3 \times 10^{9} \mathrm{cfu} /$ day [99].

A meta-analysis of RCTs indicated shorter time to full enteral feeds, fewer episodes of feed intolerance, better weight gain and growth velocity, decreased transition time from or gastric to breast feeds and increased postprandial mesenteric flow reduced duration of hospitalization, lower incidence of late-onset sepsis with no adverse effects of probiotic supplementation. Current evidence indicates that probiotic supplementation did not increase the incidence risk of sepsis or mortality and is safe and effective in reducing the risk of LOS in preterm neonates in NICU $[43,100-103]$.

Reviewed literature and Meta analysis of randomized controlled trials revealed that controversies exist for safety and efficacy of probiotics for preterm infants especially in ELBW infants. Probiotics have been found to be well tolerated by preterm low birth weight neonates but based upon evidence and efficacy and safety routine use of probiotics in ELBW infants is not recommended [43, 57, 103-107]. Recently, Sawh et al. concluded that administration of probiotics may prevent severe NEC in infants with a birth weight $<2500 \mathrm{~g}$ but did not recommend for babies with a birth weight $<1000 \mathrm{~g}$ [107]. Reviewed literature suggested administration of probiotics in premature infants for prevention of NEC, however the current evidence are not conclusive due to the heterogeneity of probiotic 
formulations (single or multiple-strains of probiotics), diverse doses $\left(10^{5}\right.$ to $\left.10^{10} \mathrm{cfu} / \mathrm{ml}\right)$ and duration of treatment [108]. Based upon reviewed literature routine use of probiotics in the preterm infant is not be recommended due to many uncertainties such as the mechanisms of action of probiotics, health effects of employed probiotics, forms of microbial adaptations and ecological consequences [109].

Millar et al. delineated various uncertainties relevant to administration of probiotics in the preterm infant as pathogenesis of NEC, impact of probiotics on early development, ecological consequences of widespread use of probiotics, microbial adaptations consequent on use of probiotics, risk groups for adverse outcomes, optimum dose and timing of intervention, impact of unintended cross-colonisation on outcome and interactions with other preventive interventions [21]. Evidence suggests that probiotics are safe but may have an adverse immunologic effect and critically sick infants in intensive care units, postoperative and hospitalized patients and patients with immune-compromised complexity were at greater risk $[95,110]$. van den Nieuwboer, et al. suggested intense analysis of safety aspects prior to consideration of probiotic therapy for preterm infants and neonates [111]. Following approaches are suggested to assess the safety of a probiotic strain.

- Assessment of pathogenicity and infectivity, deleterious metabolic activities, excessive immune response and potential gene transfer [112]

- Studies should focus on the intrinsic properties of the strain

- Studies on the pharmacokinetics (survival, activity in the intestine, dose-response relationships, faecal and mucosal recovery) of the strain

- Studies for interactions between the strain and the host [113]

- An individual risk-benefit assessment is required

- Safety and efficacy of each probiotic strain has to be proven separately [57].

\section{Future Research Requirements for Probiotic Recommendation for Preterm Infants}

- Long term gut colonization or impairment of the natural diversity of the gut microbiota due to probiotic intervention at an early age needs to be addressed [114].

- Large trials are needed to evaluate the short and long-term safety of probiotics and effect on the composition and development of the intestinal microflora especially during the first months of life is emerging as probiotics can alter immune responses and microbial-epithelial cross talk $[22,76,115,116]$.

- Determination of optimal dose, duration and selection of probiotic agents (species, strain, single or combined, live or killed) used for supplementation is emerging [77,100,103]

- Strain specific efficacy of probiotics to be determined for application in ELBW infants [39,117].

- Clinical trials are necessary to evaluate adverse effects of probiotic in higher risk subjects such as immune compromise, premature infants or patients with short bowel syndrome, central venous catheters and cardiac valve disease [118].

- Emergence of a standard methodology for assessing the intestinal flora and its mandatory adoption for conducting related studies and definite treatment protocols is required to arrive upon a conclusive result $[74,116]$.

- Research indicated that the probiotic mechanism of action can be translocated, thus increasing the risk of developing subsequent sepsis and bacteraemia, therefore determination of the optimal dosage for the best effect without side-effects, is essential [119].

- Health benefit claims of probiotic foods are still not conclusive and further studies are required to confirm its safety especially for preterm infants [109].

\section{Conclusion}

Preterm infants lack adequate intestinal commensal or "healthy" bacterial flora and abnormal pattern of colonization in preterm infants may contribute to the pathogenesis of NEC. Probiotics may promote intestinal function, maturation and defense against potential harmful pathogens and most systematic reviews reported probiotic to be safe and efficacious and can be recommend for routine administration in the preterm infants but not for ELBW infants. Breast milk is the most ideal food even for preterm infants and oral feeding with probiotics along with breast milk would exhibit a greater decline in both incidence and severity of NEC in contrast to neonates fed exclusively with breast milk.

\section{References}

1. Van't Land B, Boehm G, Garssen J. Breast milk: Components with immune modulating potential and their possible role in immune mediated disease resistance. Dietary Components and Immune Function. 2010; 25-41.

2. Lonnerdal B. Bioactive proteins in breast milk. Journal of Paediatrics and Child Health. 2013;49(S1):1-7.

3. Martin CR, Ling PR and Blackburn GL. Review of infant feeding: Key features of breast milk and infant formula. Nutrients. 2016;8(5): 279. doi: $10.3390 /$ nu8050279

4. Hanson C, Lyden E, Furtado J, Ormer MV and Anderson-Berry A. A comparison of nutritional antioxidant content in breast milk, donor milk, and infant formulas. Nutrients. 2016;8(11):E681.

5. Arslanoglu S, Ziegler EE, Moro GE and the WAPM Working Group on Nutrition. Donor human milk in preterm infant feeding: evidence and recommendations. J Perinat Med. 2010;38(4):347-351. doi: 10.1515/ JPM.2010.064

6. Underwood MA. Human milk for the premature infant. Pediatr Clin North Am. 2013;60(1):189-207. doi: 10.1016/j.pcl.2012.09.008

7. Sarkar S. Potential benefits of probiotics for preterm infants: A Review. Journal of Nutritional Therapeutics. 2016;5(2):55-63.

8. Polin RA, Denson S, Brady MT. Epidemiology and diagnosis of health care-associated infections in the NICU. Pediatrics. 2012;129(4):11041109. doi: $10.1542 /$ peds.2012-0147 
9. Anderson S. Probiotics for preterm infants: a premature or overdue necrotizing enterocolitis prevention strategy? Neonatal Netw. 2015;34(2):83-101. doi: 10.1891/0730-0832.34.2.83

10. Vongbhavit $\mathrm{K}$ and Underwood MA. Prevention of necrotizing enterocolitis though manipulation of the intestinal microbiota of the premature infant. Clinical Therapeutics. 2016;38(4):716-732. doi: 10.1016/j.clinthera.2016.01.006

11. Fong, FLY, Shah, NP and Kirjavainen P. Mechanism of action of probiotic bacteria on intestinal and systemic immunities and antigen-presenting cells. International Reviews Immunology.2015;25(3):179-188.

12. Pace F, Pace M. and Quartarone G. Probiotics in digestive diseases: focus on Lactobacillus GG, Minerva Gastroenterologica e Dietologica. 2015;61(4): 273-292.

13. Tanaka K, Fujiya M, Konishi H, Ueno N, Kashima S, Sasajima J, et al. Probiotic-derived polyphosphate improves the intestinal barrier function through the caveolin-dependent endocytic pathway. Biochemical and Biophysical Research Communications, 2015; $467(3): 541-548$.

14. Stenman LK, Burcelin R and Lahtinen S. Establishing a causal link between gut microbes, body weight gain and glucose metabolism in humans-towards treatment with probiotics". Beneficial Microbes. 2015; 7(1):11-22.

15. Thakur N, Rokana N and Panwar H. Probiotics: Selection criteria, safety and role in health and disease. Journal of Innovative Biology. 2016;3(1):259-270.

16. Nair V and Soraisham AS. Probiotics and prebiotics: Role in prevention of nosocomial sepsis in preterm infants. International Journal of Pediatrics. 2013;2013:8.

17. Bernardo WM, Aires FT, Carneiro RM, Sa FP, Rullo VE and Burns DA. Effectiveness of probiotics in the prophylaxis of necrotizing enterocolitis in preterm neonates: a systematic review and metaanalysis. Journal of Pediatric. 2013;89(1):18-24. doi: 10.1016/j. jped.2013.02.004

18. Hartel C, Pagel J, Rupp J, Bendiks M, Guthmann F, Rieger-Fackeldey E, et al. Prophylactic use of Lactobacillus acidophilus/Bifidobacterium infantis probiotics and outcome in very low birth weight infants. J Pediatr. 2014;165(2): 285-289. doi: 10.1016/j.jpeds.2014.04.029

19. Viswanathan S, Lau C, Akbari H, Hoyen C and Walsh MC. Survey and evidence based review of probiotics used in very low birth weight preterm infants within the United States. J Perinatol. 2016;36(12):1106-1111

20. Lambaek ID, Fonnest G, Gormsen M, Brok J, Greisen G. Probiotics to prevent necrotising enterocolitis in very preterm infants. Dan Med J. 2016;63(3):A5203

21. Millar M, Wilks M, Fleming $P$ and Costeloe K. Should the use of probiotics in the preterm be routine? Arch Dis Child Fetal Neonatal Ed. 2012;97(1):F70-74. doi: 10.1136/adc.2009.178939

22. Indrio $\mathrm{F}$ and $\mathrm{Neu}$ J. The intestinal microbiome of infants and the use of probiotics. Curr Opin Pediatr. 2011;23(2):145-150. doi: 10.1097/ MOP.0b013e3283444ccb

23. Bennet $\mathrm{R}$ and Nord CE. Development of the fecal anaerobic microflora after cesarean section and treatment with antibiotics in newborn infant. Infection. 1987;15(5):332-336.

24. Favier CF, Vaughan EE, Devos WM and Akkermans ADL. Molecular monitoring of succession of bacterial communities in human neonates. Appl Environ Microbiol. 2002;68(1):219-226.
25. Matamoros S, Gras-Leguen C, Vacon FL, Potel G and de La Cochetiere MF. Development of intestinal microbiota in infants and its impact on health. Trends Microbiol. 2013;21(4):167-173. doi: 10.1016/j. tim.2012.12.001

26. Carlisle EM, Morowitz MM. The intestinal microbiome and necrotizing enterocolitis. Curr Opin Pediatr. 2013;25(3):382-387. doi: 10.1097/ MOP.0b013e3283600e91

27. MillarM, Wilks M, Costeloe K. Probiotics for preterm infants? Archives of Disease in Childhood - Fetal and Neonatal Edition. 2003;88:354358.

28. Murguia-Peniche T, Mihatsch WA, Zegarra J, Supapannachart S, Ding ZY and Neu J. Intestinal mucosal defense system - Part 2, Probiotics and Prebiotics. J Pediatr. 2013;162( 3 suppl):S64-71. doi: 10.1016/j. jpeds.2012.11.055

29. Patel RM, Denning PW. Therapeutic use of prebiotics, probiotics and postbiotics to prevent necrotizing enterocolitis: what is the current evidence? Clin Perinatol. 2013;40(1):11-25. doi: 10.1016/j. clp.2012.12.002

30. Jakaitis BM and Denning PW. Commensal and probiotic bacteria may prevent NEC by maturing intestinal host defenses. Pathophysiology. 2014;21(1):47-54. doi: 10.1016/j.pathophys.2013.11.012

31. Penders J, Thijis C, Vink C, Stelma FF, Snijders B, Kummeling I, et al. Factors influencing the composition of the intestinal microbiota in early infancy. Pediatrics. 2006;118(2):511-521.

32. Stenger MR, Reber KM, Giannone PJ and Nankervis CA. Probiotics and prebiotics for the prevention of necrotizing enterocolitis. Curr Infect Dis Rep. 2011;13(1):13-20. doi: 10.1007/s11908-010-0156-6

33. Berrington JE, Stewart CJ, Embleton ND and Cummings SP. Gut microbiota in preterm infants: assessment and relevance to health and disease. Arch Dis Child Fetal Neonatal Ed. 2013;98(4):286-290. doi: 10.1136/archdischild-2012-302134

34. Cilieborg MS, Boye M, Sangild PT. Bacterial colonization and gut development in preterm neonates. Early Human Dev. 2012;88 suppl 1:41-49. doi: 10.1016/j.earlhumdev.2011.12.027

35. FAO/WHO (2001). Regulatory and clinical aspects of dairy probiotics. Food and Agriculture Organization of the United Nations, World Health Organization Cordoba, Argentina.

36. Hill C, Guarner F, Reid G, Gibson GR, Merenstein DJ, Pot B, et al. Expert consensus document. The International Scientific Association for Probiotics and Prebiotics consensus statement on the scope and appropriate use of the term probiotic. Nat Rev Gastroenterol Hepatol. 2014;11(8):506-514. doi: 10.1038/nrgastro.2014.66

37. Dani C, Biadaioli R, Bertini G, Martelli E and Rubaltelli FF. Probiotics feeding in prevention of urinary tract infection, bacterial sepsis and necrotizing enterocolitis in preterm infants. A prospective doubleblind study. Biol Neonate. 2002;82(2):103-108.

38. Hardy H, Harris J, Lyon E, Beal J and Foey AD. Probiotics, prebiotics and immunomodulation of gut mucosal defences: homeostasis and immunopathology. Nutrients. 2013;5(6):1869-1912. doi: 10.3390/ nu5061869

39. Wang Q Dong J and Zhu Y. Probiotic supplement reduces risk of necrotizing enterocolitis and mortality in preterm very low birth- weight infants: an updated meta-analysis of 20 randomized, controlled trials. J Pediatr Surg. 2012;47(1):241-248. doi: 10.1016/j. jpedsurg.2011.09.064 
40. Raguz MJ, Brzica J, Rozic S, Glamuzina DS, Mustapic A, Bosnjak MN The impact of probiotics (Lactobacillus reuteri Protectis) on the treatment, course and outcome of premature infants in the Intensive Care Unit in Mostar. Journal of Pediatric and Neonatal Individualized Medicine. 2016;5(2): e050228

41. Li D, Rosito G and Slagle T. Probiotics for the prevention of necrotizing enterocolitis in neonates: an 8-year retrospective cohort study. J Clin Pharm Ther. 2013;38(6):445-449. doi: 10.1111/jcpt.12084

42. Conca N. Probiotic supplementation and late-onset sepsis in preterm infants: a meta-analysis. Review Chilena Infectology. 2016;33:239.

43. Rao SC, Athalye-Jape GK, Deshpande GC, Simmer KN and Patole SK. Probiotic Supplementation and late-onset sepsis in preterm infants: A meta-analysis. Pediatrics. 2016;137(3):e20153684. doi: 10.1542/ peds.2015-3684

44. Rijkers GT, Bengmark S, Enck P, Haller D, Herz U, Kallioma ki M et al. Guidance for substantiating the evidence for beneficial effects of probiotics: current status and recommendations for future research. J Nutr. 2010;140(3):671S-676S. doi: 10.3945/jn.109.113779

45. Fijan S. Microorganisms with claimed probiotic properties: An Overview of recent literature. Int J Environ Res Public Health. 2014;11(5):4745-4767. doi: 10.3390/ijerph110504745

46. Rouge C, Piloquet H, Butel MJ, Berger B, Rochat F, Ferraris L. Oral supplementation with probiotics in very-low-birth-weight preterm infants: a randomized, double-blind, placebo-controlled trial. Am J Clin Nutr. 2009; 89(6):1828-1835. doi: 10.3945/ajcn.2008.26919

47. Millar MR, Bacon C, Smith SL, Walker V and Hall MA. Enteral feeding of premature infants with Lactobacillus GG. Arch Dis Child. 1993;69:483487.

48. Hoyos AB. Reduced incidence of necrotizing enterocolitis associated with enteral administration of Lactobacillus acidophilus and Bifidobacterium infantis to neonates in an intensive care unit. Int J Infect Dis. 1999;3(4):197-202.

49. Bin-Nun A, Bromikerm R, Wilschanskim M, Kaplan M, Rudensky B. Oral probiotics prevent necrotizing enterocolitis in very low birth weight neonates. J Pediatrics. 2005;147(2):192-196.

50. Lin HC, Su BH, Chen AC, Lin TW, Tsai CH, Yeh TF and Oh W. Oral probiotics reduce the incidence and severity of necrotizing enterocolitis in very low birth weight infants. Pediatrics. 2005;115(1):1-4.

51. Lee SJ, Cho SJ and Park EA. Effects of probiotics on enteric flora and feeding tolerance in preterm infants. Neonatology. 2007;91(3):174179.

52. Lin HC, Hsu CH, Chen HL, Chung MY, Hsu JF, Lien RI, et al. Oral probiotics prevent necrotizing enterocolitis in very low birth weight preterm infants: a multicenter, randomized, controlled trial. Pediatrics. 2008;122(4):693-700. doi: 10.1542/peds.2007-3007

53. Samanta M, Sarkar M, Ghosh P, Ghosh JK, Sinha MK, Chatterjee S Prophylactic probiotics for prevention of necrotizing enterocolitis in very low birth weight newborns. Journal of Tropical Pediatrics. 2009;55(2):128-131.

54. Awad H, Mokhtar H, Imam SS, Gad GI, Hafez H, Aboushady N Comparison between killed and living probiotic usage versus placebo for the prevention of necrotizing enterocolitis and sepsis in neonates. Pak J Biol Sci. 2010;13(6):253-262.

55.Sari FN, Dizdar EA, Oguz S, Erdeve O, Uras N and Dilmen U. Oral probiotics: Lactobacillus sporogenes for prevention of necrotizing enterocolitis in very low-birth weight infants: a randomized, controlled trial. Eur J Clin Nutr. 2011;65: 434-439. doi: 10.1038/ejcn.2010.278

56. Braga TD, da Silva GAP, de Lira PIC, de Carvalho Lima M. Efficacy of Bifidobacterium breve and Lactobacillus casei oral supplementation on necrotizing enterocolitis in very-low-birth-weight preterm infants: a double-blind, randomized, controlled trial. Am J Clin Nutr. 2011;93(1): 81-86. doi: 10.3945/ajcn.2010.29799

57. Mihatsch WA, Braegger CP, Decsi T, Kolacek S, Lanzinger H, Mayer B, et al. Critical systematic review of the level of evidence for routine use of probiotics for reduction of mortality and prevention of necrotizing enterocolitis and sepsis in preterm infants. Clinical Nutrition. 2012; 31(1):6-15. doi: 10.1016/j.clnu.2011.09.004

58. Hunter C, Dimaguila MA, Gal P, Wimmer Jr JE, Ransom JL, Carlos, et al. Effect of routine probiotic, Lactobacillus reuteri DSM 17938, use on rates of necrotizing enterocolitis in neonates with birthweight < 1000 grams: a sequential analysis. BMC Pediatric. 2012;12:142. doi: 10.1186/1471-2431-12-142

59. Al-Hosni M, Duenas M, Hawk M, Stewart LA, Borghese RA, Cahoon, M. Probiotics supplemented feeding in extremely low-birthweight infants. Journal of Perinatology. 2011;32:253-259.

60. Fernandez-Carrocer, LA, Solis-Herrera A, Cabanillas-Ayon M, GallardoSarmiento RB, Garcia-Pere CS, Montano-Rodriguez R, et al. Doubleblind, randomized clinical assay to evaluate the efficacy of probiotics in preterm newborns weighing less than 1,500 $\mathrm{g}$ in the prevention of necrotizing enterocolitis. Arch Dis Child Fetal Neonatal Ed. 2013;98(1):F5-9. doi: 10.1136/archdischild-2011-300435

61. Demirel G, Erdeve O, Celik IH, Dilmen U. Saccharomyces boulardii for prevention of necrotizingenterocolitisin preterminfants:arandomized, controlled study. Acta Paediatric. 2013;102(12):e560-e565. doi: 10.1111/apa.12416

62. Bonsante F, Iacobelli S, Gouyon JB. Routine probiotic use in very preterm infants: Retrospective comparison of two Cohorts. Am J Perinatol. 2013;30(1):41-46. doi: 10.1055/s-0032-1321498

63. Serce 0, Benzer D, Gursoy T, Karatekin, Ovali F. Efficacy of Saccharomyces boulardii on necrotizing enterocolitis or sepsis in very low birth weight infants: a randomised controlled trial. Early Hum Dev. 2013; 89(12):1033-1036. doi: 10.1016/j.earlhumdev.2013.08.013

64. Jacobs SE, Tobin JM, Opie GF, Donath S, Tabrizi SN, et al. Probiotic effects on late-onset sepsis in very preterm infants: A Randomized Controlled Trial. Pediatrics. 2013;132(6):1055-1062. doi: 10.1542/ peds.2013-1339

65. Costeloe KL, Wilks M, Hardy P, Nelis C, Millar MR. Early Bifidobacterium breve BBG-001 to prevent necrotising enterocolitis, late-onset sepsis and death: the pips trial. Archives of Disease in Childhood. 99:3-24.

66. Janvier A, Malo J, Barrington KJ. Cohort study of probiotics in a North American neonatal intensive care unit. J Pediatr. 2014;164(5):980985. doi: $10.1016 /$ j.jpeds.2013.11.025

67. Manzoni P, Meyerb M, Stolfi I, Rinaldi M, Cattani S, Pugni L. Bovine lactoferrin supplementation for prevention of necrotizing enterocolitis in very-low-birth-weight neonates: a randomized clinical trial. Early Human Development. 2014;90(1):S60-S65

68. Oncel MY, Sari FN, Arayici S, Guzoglu N, Erdeve O, Uras N. Lactobacillus reuteri for the prevention of necrotizing enterocolitis in very low birthweight infants: a randomised controlled trial. Arch Dis Child Fetal Neonatal Ed. 2014;99(2): 110-115. doi: 10.1136/ archdischild-2013-304745

69. Saengtawesin V, Tangpolkaiwalsak R, Kanjanapattankul W. Effect of oral probiotics supplementation in the prevention of necrotizing 
enterocolitis among very low birth weight preterm infants. J Med Assoc Thai. 2014;97(suppl 6):S20-S25.

70. Guthmann F, Arlettaz Mieth RP, Bucher HU, Buhrer C. Short courses of dual-strain probiotics appear to be effective in reducing necrotising enterocolitis. Acta Paediatr. 2016;105(3): 255-259. doi: 10.1111/ apa.13280

71. Dilli D, Aydin B, Fettah ND, Ozyazıcı E, Beken S, Zenciroglu A. The propre-save study: effects of probiotics and prebiotics alone or combined on necrotizing enterocolitis in very low birth weight infants. J Pediatr. 2015;166(3):545-551. doi: 10.1016/j.jpeds.2014.12.004

72. Meha T, Jaiswal AK, Raja A, Sinha AK. Role of oral probiotics in prevention of necrotising enterocolitis in preterm neonates in a tertiary care centre in Northern India. International Journal of Contemporary Pediatrics. 2016;3(4):1293-1296.

73. Chowdhury T, Ali MM, Hossain MM, Singh J, Yousuf ANM, Yasmin F. Efficacy of probiotics versus placebo in the prevention of necrotizing enterocolitis in preterm very low birth weight infants: A DoubleBlind Randomized Controlled Trial. J Coll Physicians Surg Pak 2016;26(9):770-774. doi: 2433

74. Costeloe K, Hardy P, Juszczak E, Wilks M, Millar MR. Bifidobacterium breve BBG-001 in very preterm infants: a randomised controlled phase 3 trial. Lancet. 2016;387:649-660

75. AlFaleh K, Anabrees J. Efficacy and safety of probiotics in preterm infants. J Neonatal Perinatal Med. 2013;6(1):1-9. doi: 10.3233/NPM1363712

76. Wang XL, Li X, Kang L, Wang SH. Prophylactic probiotics for preventing necrotizing enterocolitis and reducing mortality in very low birth weight infants: a Meta analysis. Zhongguo Dang Dai Er Ke Za Zhi. 2015;17(8):852-858

77. Olsen R, Greisen G, Schroder M, Brok J. Prophylactic probiotics for preterm infants: A systematic review and meta-analysis of observational studies. Neonatology. 2016; 109(2):105-112. doi: $10.1159 / 000441274$

78. Urbanska M, Szajewska H. The efficacy of Lactobacillus reuteri DSM 17938 in infants and children: a review of the current evidence. Eur Pediatr. 2014;173(10):1327-1337. doi: 10.1007/s00431-014-2328-0

79. Roy A, Chaudhuri J, Sarkar D, Ghosh P, Chakraborty S. Role of enteric supplementation of probiotics on late-onset sepsis by Candida species in preterm low birth weight neonates: A randomized, double blind, placebo-controlled trial. N Am J Med Sci. 2014;6(1):50-57. doi: $10.4103 / 1947-2714.125870$

80. Denkel LA, Schwab F, Garten L, Geffers C, Gastmeier P, Piening B. Protective Effect of dual-strain probiotics in preterm infants: A multicenter time series analysis. Plos One. 2016;11(6): e0158136. doi: 10.1371/journal.pone.0158136

81. Cruchet S, Furnes R, Maruy A, Hebel E, Palacios J, Medina F, et al. The use of probiotics in pediatric gastroenterology: A review of the literature and recommendations by Latin-American Experts. Pediatr Drugs. 2015;17(3):199-216. doi: 10.1007/s40272-015-0124-6

82. Orrhage K, Nord CE. Factors controlling the bacterial colonization of the intestine in breastfed infants. Acta Paediatrica suppl 1999;88(430):47-57.

83. Mattar AF, Drongowski RA, Coran AG, Harmon CM. Effect of probiotics on enterocyte bacterial translocation in vitro. Pediatr Surg Int 2001;17(4): 265-268

84. Reid G, Howard J, Gan BS. Can bacterial interference prevent infection? Trends Microbiol. 2001; 9(9): 424-428.
85. Duffy LC. Interactions mediating bacterial translocation in the immature intestine. Journal of Nutrition. 2000;130(2):432S-436S.

86. Lin PW, Stoll BJ. Necrotising enterocolitis. Lancet. 2006;368(9543):1271-1283.

87. Neu J, Walker, W.A. Necrotizing enterocolitis. The New England Journal of Medicine. 2011:364:255-264. doi: 10.1056/NEJMra1005408

88. Schanler RJ. Probiotics and necrotising enterocolitis in premature neonates. Arch Dis Child Fetal Neonatal Ed. 2006;91(6): F395-F397. doi: 10.1136/adc.2005.092742

89. Caplan MS, Jilling T. Neonatal necrotizing enterocolitis: possible role of probiotic supplementation. Journal of Pediatric Gastroenterology Nutrition. 2000;30(p S18-S22):18-22.

90. Holzapfel WH, Haberer P, Snel J, Schillinger U, Huis in't Veld JH. Overview of gut flora and probiotics. Int J Food Microbiol. 1998;41(2): 85-101.

91. Marteau P. Safety aspects of probiotic products. Scandivian Journal of Nutrition. 2016;45:22-30.

92. Marteau P and Seksik P. Tolerance of probiotics and prebiotics. J Clin Gastroenterol. 2004;38( 6 suppl):S67-69.

93. Taranto MP, Vera JL, Hugenholtz J, De Valdez GF, Sesma F. Lactobacillus reuteri CRL1098 produces cobalamin. J Bacteriol. 2003;185(18):56435647.

94. Sharp RR, Achkar JP, Brinich MA and Farrell RM. Helping patients make informed choices about probiotics: a need for research. Am J Gastroenterol. 2009;104(4):809-813. doi: 10.1038/ajg.2008.68

95. Didari T, Solki S, Mozaffari S, Nikfar S and Abdollahi M. A systematic review of the safety of probiotics. Expert Opin Drug Saf. 2014;13:227 239. doi: $10.1517 / 14740338.2014 .872627$

96. FAO/WHO (2002), "Guidelines for the Evaluation of Probiotics in Food", Joint FAO/WHO Working Group Report on Drafting, London, Ontario, Canada.

97. Braegger C, Chmielewska A, Decsi T, Kolacek S, Mihatsch W, Moreno L. Supplementation of infant formula with probiotics and/or prebiotics: a systematic review and comment by the ESPGHAN, Committee on Nutrition. Journal of Pediatric Gastroenterology Nutrition. 2011;52:238-250

98. Downard CD, Renaud E, St Peter SD, Abdullah F, Islam S, Saito. Treatment of necrotizing enterocolitis: an American pediatric surgical association outcomes and clinical trials committee systematic review. Journal of Pediatric Surgery. 2012;47(11):2111-2122.

99. Deshpande G, Rao S, Patole S and Bulsara M. Updated meta-analysis of probiotics for preventing necrotizing enterocolitis in preterm neonates. Pediatrics. 2010;125(5):921-930. doi: 10.1542/peds.20091301

100. Athalye-Jape G, Deshpande G, Rao S and Patole S. Benefits of probiotics on enteral nutrition in preterm neonates: a systematic review. Am J Clin Nutr. 2014;100(6):1508-1519. doi: 10.3945/ajcn.114.092551

101. Athalye-Jape G, Rao S and Patole S. “Lactobacillus reuteri DSM 17938 as a probiotic for preterm neonates: a strain-specific systematic review". Journal of Parenteral and Enteral Nutrition. 2016;40(6):783794. doi: $10.1177 / 0148607115588113$

102. Yang Y, Guo Y, Kan Q, Zhou X G, Zhou X Y and Li Y. "A meta-analysis of probiotics for preventing necrotizing enterocolitis in preterm neonates". Brazilian Journal of Medical and Biological Research. 2014;47(9):804-810. 
103.Zhang GQ Hu H J, Liu C Y, Shakya S and Li Z Y. "Probiotics for preventing late-onset sepsis in preterm neonates". 2016;95(8):2581. doi: 10.1097/MD.0000000000002581

104. Xin G and Juan L. "Research progress of the application of probiotics in preterm infants". Chinese Journal of Contemporary Pediatric. 2016;18(9):909-914

105. AlFaleh K and Bassler D. "Probiotics for prevention of necrotizing enterocolitis in preterm infants". Cochrane Database of Systematic Review. 2011;16(3):CD005496. doi: 10.1002/14651858.CD005496

106. Shlomai N O, Deshpande G, Rao S and Patole S. "Probiotics for Preterm Neonates: What Will It Take to Change Clinical Practice?". Neonatology. 2014;105(1):64-70. doi: 10.1159/000354891

107. Sawh S C, Deshpande S, Jansen S, Reynaert C J and Jones P M. "Prevention of necrotizing enterocolitis with probiotics: a systematic review and meta-analysis". 2016;5(4):e2429. doi: 10.7717/peerj.2429

108. Qasem W, Alnaqi A, Jorgensen S and Friel J. "Probiotics and synbiotics in necrotizing enterocolitis: Where are we?". Journal of Pediatric Neonatal Care. 2014;1(1):00007.

109. Sarkar S, Sur A, Das K, Boral J. Safety of Probiotics for Preterm Infants - A Review. Nutrition and Food Toxicology. 2017;1:219-227.

110. Hibberd P L and Davidson L. "Probiotic foods and drugs: impact of US regulatory status on design of clinical trials". Clinical Infectious Disease. 2008;46(2):137-140. doi: 10.1086/523321

111. van den Nieuwboer M, Claassen E, Morelli L, Guarner F and Brummer R J. "Probiotic and symbiotic safety in infants under two years of age". Beneficial Microbes. 2014;5(1):45-60. doi: 10.3920/BM2013.0046
112. Zhang Z, Liu C and Guo X. "Safety of probiotics a review". Acta Microbiologica Sinica. 2008;48(2):257-261.

113. Soccol C R, Vandenberghe L P, Spier M R, Medeiros A B P, Yamaguishi C T, Lindner J D, et al. The potential of probiotics: a review. Food Technology Biotechnology. 2010;48(4):413-34.

114. Isolauri E. "Probiotics in preterm infants: A controversial issue". Journal of Pediatric Gastroenterology Nutrition. 2007;45(3):188-189.

115. Bertelsen R J, Jensen E T and Ringel-Kulka T. "Use of probiotics and prebiotics in infant feeding". Best Practice and Research Clinical Gastroenterology. 2016;30(1):39-48. doi: 10.1016/j.bpg.2016.01.001

116. Sarkar S. "Probiotics, prebiotics and synbiotics for infant feeding - A Review”. Journal of Microbial Biochemical Technology. 2011;S1:004. doi: 10.4172/1948-5948.S1-004

117. Aceti A, Gori D, Barone G, Callegari M L, Mauro A D, Fantini M P. "Probiotics for prevention of necrotizing enterocolitis in preterm infants: systematic review and meta-analysis". Italian Journal of Pediatrics. 2015;41:89. doi: 10.1186/s13052-015-0199-2

118. Doron S and David R. "Snydman risk and safety of probiotics". Clinical Infectious Diseases. 2015;60(2):129-134.

119. DiCerbo A, Palmieri B, Aponte M, Morales-Medina J C and Iannitti T. "Mechanisms and therapeutic effectiveness of lactobacilli". Journal of Clinical Pathology. 2016;69(3):187-203. doi: 10.1136/ jclinpath-2015-202976 